\title{
Kava-kava como aditivo fitoterápico na alimentação de codornas de postura
}

\author{
Janaina Della Torre da Silva ${ }^{1^{*}}$ \\ Aline Rocha Guarini ${ }^{1}$ \\ Luciana Thie Seki Dias ${ }^{2}$ \\ Fabricio Hirota Hada ${ }^{1}$ \\ Rodrigo Antonio Gravena ${ }^{1}$ \\ Rafael Henrique Marques ${ }^{1}$ \\ Vera Maria Barbosa de Moraes ${ }^{1}$

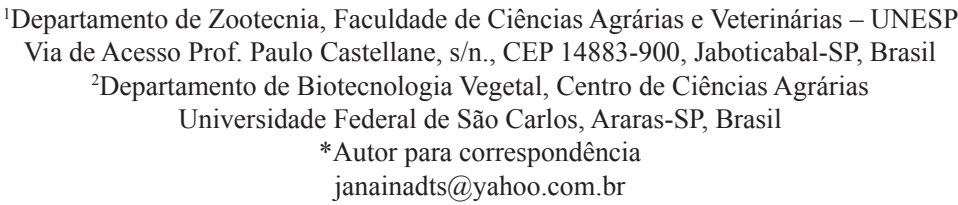

\section{Resumo}

Este estudo teve como objetivo avaliar o efeito da kava-kava (Piper methysticum) como fitoterápico na alimentação de codornas na fase de postura. Avaliou-se o desempenho (consumo de ração, conversão alimentar, peso dos ovos e produção), qualidade de ovos, tempo em imobilidade tônica (TIT), intensidade de ferimentos e relação heterófilo: linfócito (H:L). Foram utilizadas 90 codornas com 21 semanas de idade, divididas em blocos ao acaso e submetidas a três tratamentos $(0,300$ e $600 \mathrm{mg}$ de extrato seco de kava-kava/kg de ração), cinco repetições e seis aves por parcela. A kava-kava utilizada na alimentação de codornas de postura não tem efeito sobre o desempenho, qualidade de ovos, intensidade de ferimentos e relação H:L, entretanto ocorre redução no tempo de permanência em imobilidade tônica com a inclusão de kava-kava, o que predispõe a uma redução do estresse.

Unitermos: comportamento, Coturnix coturnix, estresse, fitoterápico, ovos, Piper methysticum

\section{Abstract}

Kava-kava as a herbal additive in feed for laying quails. The objective of this study was to evaluate the effect of dietary kava-kava (Piper methysticum) during the laying period on performance (feed intake, feed conversion, weight of eggs and production), egg quality, tonic immobility time (TIT), intensity of injuries and blood heterophil/lymphocyte ratio (H:L). A total of 90 female Japanese quails of 21 weeks of age were distributed in a completely randomized experimental design and submitted to three treatments $(0,300$ and $600 \mathrm{mg}$ of dried extract of kava-kava/kg of feed), with five replicates and six birds, in each batch. Kava-kava fed to laying quails has no effect on performance, egg quality, intensity of injury or H:L ratio. However, there is a reduction in time spent in tonic immobility with the inclusion of kava-kava that predisposes the quail to a reduction of stress.

Key words: behavior, Coturnix coturnix, eggs, phytotherapic, Piper methysticum, stress 


\section{Introdução}

A criação de codornas vem se destacando a cada ano no mercado agropecuário brasileiro. A partir de 1990, observou-se rápida expansão da produção do setor coturnícola, principalmente com o início da comercialização de ovos beneficiados (descascados ou em conserva), que agregou valor ao produto (Belo et al., 2000). Além disso, as codornas são aves de alta precocidade e capacidade produtiva e, devido a isso, vem despertando cada vez mais o interesse de produtores e pesquisadores. No Brasil, a coturnicultura destina-se principalmente a produção de ovos, firmando-se nos últimos anos como importante segmento no cenário avícola industrial (Laganá et al., 2009).

No entanto, a produção de ovos pode ser afetada pelo estresse que agrava o comportamento nervoso e agitado das codornas, fazendo com que elas se biquem e gastem energia com comportamentos agressivos, prejudicando a produção e o bem-estar do plantel (Silva, 2006). As bicadas agressivas causam sérias lesões na pele, olhos, ouvidos, podendo levar a perda da visão ou até a morte, tornando-se um importante problema de bem-estar (Schmid e Wechsler, 1997).

Quando expostas a predadores ou a situações novas, as codornas apresentam comportamento de medo ou estresse que as levam ao estado de imobilidade que persiste durante alguns segundos até horas, dependendo do estresse sofrido pelas aves (Jones e Mills, 1999).

O estresse fisiológico, incluindo contenção física, mudança de ambiente, medo, dor, transporte, frio ou fome, causa heterofilia, assim como outros eventos que induzam atividade adrenal como conflito entre os animais. Estudos controlados em frangos sugerem que a proporção entre heterófilos e linfócitos pode ser uma medida de estresse mais confiável que a corticosterona (Maxwell, 1993; Vleck et al., 2000; Ruiz et al., 2002; Scope et al., 2002; Borges et al., 2003; Landers et al., 2007).

Estudos com fitoterápicos de caráter ansiolítico e sedativo como a passiflora, valeriana e camomila, têm sido realizados com o intuito de se diminuir o estresse em codornas e, dessa forma, melhorar o desempenho e o bem-estar dessas aves (Silva, 2006; Marques, 2007).

A kava-kava (Piper methysticum), fitoterápico indicado no tratamento de ansiedade, tensão nervosa, estresse, agitação e insônia, poderia ser uma alternativa para melhorar o desempenho de codornas e amenizar o estresse que acomete essas aves (Pittler e Ernst, 2000).

As substâncias com propriedades medicinais da kava-kava localizam-se na raiz e no rizoma, sendo estas as partes utilizadas no preparo dos extratos secos. Tem como princípios ativos (substâncias que exercerão efeito farmacológico) as cavapironas, dentre as principais a cavaína, dihidrocavaína, iangonina, desmetoxi-iangonina, metisticina e dihidrometisticina (Arruda et al., 2005), responsáveis pelas propriedades ansiolítica e antidepressiva do fitoterápico. No entanto, dados relativos à hepatoxicidade têm limitado o uso de medicamentos à base de kava-kava (Clouatre, 2004; Ulbricht et al., 2005).

Estudos farmacológicos demonstraram que os princípios ativos da kava-kava promovem efeito relaxante nos músculos, particularmente útil em estados de tensão, possuem efeito analgésico, controlam a ansiedade, previnem convulsões e podem proteger o cérebro contra as injúrias provocadas por pancadas. Porém, o complexo natural de cavapirona é farmacologicamente superior aos componentes individuais isolados devido ao sinergismo existente entre todas as cavapironas ativas (Scherer, 1998).

A kava-kava tem sido testada a fim de que seus efeitos sejam comparados aos dos tradicionais benzodiazepínicos no controle da ansiedade, com resultados favoráveis ao fitoterápico, pois não apresenta os efeitos colaterais comuns aos benzodiazepínicos como a sonolência e redução da função mental (Lim et al., 2007).

Neste contexto, o presente trabalho teve como objetivo avaliar o efeito de diferentes inclusões do extrato seco de kava-kava na alimentação de codornas na fase de postura sobre desempenho, qualidade de ovos, tempo em imobilidade tônica, intensidade de ferimentos e relação heterófilo: linfócito.

\section{Material e Métodos}

O experimento foi realizado no setor de Avicultura do Departamento de Zootecnia da Faculdade de Ciências 
Agrárias e Veterinárias - Campus de Jaboticabal Unesp.

Noventa codornas com 21 semanas de idade foram pesadas e alojadas em gaiolas medindo $32 \times 36 \times 16 \mathrm{~cm}$, nas quais permaneceram por uma semana para adaptação. As gaiolas de postura eram dispostas em degraus que ficavam a $70 \mathrm{~cm}$ do piso do galpão. Os bebedouros utilizados eram do tipo nipple e a ração era fornecida em comedouro contínuo de chapa galvanizada.

As codornas foram distribuídas em blocos ao acaso, para controle do peso no início do experimento, submetidas a três tratamentos $(0$ - controle, 300 e $600 \mathrm{mg}$ de kava-kava/ $\mathrm{kg}$ de ração), com cinco repetições e seis codornas em cada parcela.

O extrato seco de kava-kava utilizado neste estudo foi adquirido em farmárcia de manipulação, sendo obtido do rizoma da planta que é a parte utilizada para a fabricação de medicamentos. A dosagem administrada teve como base a quantidade recomendada para unidade de peso para humanos, pois não se tem relatos na literatura do uso deste fitoterápico para aves.

As rações fornecidas foram isoprotéicas (18\% PB) e isoenergéticas $(2800 \mathrm{kcal} \mathrm{EM} / \mathrm{kg})$, com alteração nas quantidades de kava-kava para seus respectivos tratamentos. O balanceamento das rações seguiu as tabelas de composição de ingredientes propostas por Rostagno et al. (2005), estando as exigências nutricionais de acordo com as sugestões feitas por Murakami (1991). O programa de luz adotado foi o de $17 \mathrm{~h}$ de luz por dia.

A produção de ovos foi registrada diariamente, iniciando-se depois de um período de 15 dias nos quais as aves se adaptaram as dietas experimentais. A partir dessa data, a cada 14 dias estabeleceu-se um novo ciclo de produção até se completar quatro ciclos.

Ao término de cada ciclo foi realizada a pesagem da sobra de ração e dos ovos de cada repetição, sendo a pesagem dos ovos realizada nos três últimos dias de cada ciclo. Dessa forma, foi possível avaliar o consumo de ração e a conversão alimentar (consumo de ração/dúzia de ovos e consumo de ração/massa de ovos). A produção de ovos foi calculada para cada repetição da seguinte forma: \{[(total de ovos produzidos em 1 ciclo por parcela) $/ \mathrm{n}^{\circ}$ de aves na parcela] $/ 14$ dias $\}$ x 100 .
O tempo em imobilidade tônica (TIT) e a intensidade dos ferimentos, na cabeça e no corpo, foram avaliados no final de cada ciclo de produção, totalizando quatro avaliações.

Para a avaliação do TIT, todas as aves de uma mesma gaiola foram colocadas em uma caixa e, uma codorna por vez era virada abruptamente e colocada em decúbito dorsal em uma mesa. Antes de tirar a mão da ave, era feita uma leve pressão, de aproximadamente três segundos sobre o animal. Depois desse procedimento, iniciou-se a contagem do tempo em que permaneceram em imobilidade com o auxílio de um cronômetro digital. Para ser considerado estado de imobilidade tônica, a ave deveria permanecer imóvel por no mínimo 10 segundos (Heiblum et al., 1998).

A intensidade de ferimentos foi avaliada nos mesmos dias em que se realizou o teste de imobilidade tônica, sempre no período da manhã, seguindo-se a metodologia descrita por Savory et al. (1999). Para essa avaliação, observou-se a presença ou ausência de lesões nas diferentes partes do corpo (cabeça e corpo) de cada ave.

No término da oitava semana experimental, ou seja, quando as aves completaram 29 semanas de idade, foram coletadas amostras de sangue de três aves ao acaso por parcela, perfazendo o total de 45 amostras. O sangue, obtido por punção da veia braquial, foi utilizado na confecção das lâminas para a contagem de heterófilos e linfócitos de acordo com o descrito por Campo e Dávila (2002).

As análises estatísticas foram realizadas com a média dos quatro ciclos avaliados, pelo procedimento GLM do SAS $^{\circledR}$ (Statistical Analysis System, 1995). Para verificar a significância entre as médias dos tratamentos foi utilizado o teste de Tukey, ao nível de $5 \%$ de probabilidade. Os dados referentes à intensidade de ferimentos e expressão do comportamento foram avaliados pelo teste de Qui-quadrado.

\section{Resultados e Discussão}

Não foram observadas diferenças significativas $(\mathrm{P}>0,05)$ entre os diferentes tratamentos para consumo diário, conversão alimentar (consumo/dúzia e kg de ovos) e porcentagem de postura (Tabela 1). 
TABELA 1: Valores médios obtidos para consumo diário de ração (CRD), conversão alimentar (CA) (consumo/dúzia e consumo/ $\mathrm{kg}$ de ovos), porcentagem de postura e viabilidade de codornas submetidas a diferentes níveis de kava-kava na dieta durante a fase de postura.

\begin{tabular}{ccccc}
\hline $\begin{array}{c}\text { kava-kava } \\
\text { (mg) }\end{array}$ & CRD (g) & CA/dúzia & $\begin{array}{c}\text { CA/kg de } \\
\text { ovos }\end{array}$ & \% Postura \\
\hline 0 & 22,43 & 0,29 & 2,21 & 88,15 \\
300 & 21,90 & 0,30 & 2,20 & 84,88 \\
600 & 21,45 & 0,28 & 2,12 & 89,64 \\
\hline P value & 0,05 & 0,19 & 0,24 & 0,55 \\
CV (\%) & 3,78 & 7,02 & 6,26 & 6,04 \\
\hline
\end{tabular}

Resultados semelhantes foram descritos por Silva (2006), Marques (2007) e Gravena et al. (2009) ao avaliarem o desempenho produtivo de codornas em postura alimentadas com níveis crescentes de passiflora, camomila e valeriana $(0,250,500$ e $750 \mathrm{mg} / \mathrm{kg}$ de ração) na dieta, sendo que estes autores não verificaram efeito dos fitoterápicos no consumo e viabilidade das aves.

Não houve diferença entre os tratamentos para os parâmetros de qualidade de ovos (Tabela 2). É importante salientar que, devido à ausência de estudos sobre desempenho e qualidade de ovos de codornas, submetidos a tratamento fitoterápico com fins ansiolítico e sedativo, com base na literatura consultada, não é possível obter-se uma explicação mais aprofundada de como a kava-kava atua sobre a fisiologia das aves.

TABELA 2: Valores médios obtidos para qualidade externa e interna de ovos de codornas submetidas a diferentes níveis de kavakava na dieta durante a fase de postura.

\begin{tabular}{cccccc}
\hline $\begin{array}{c}\text { kava- } \\
\text { kava } \\
(\mathbf{m g})\end{array}$ & $\begin{array}{c}\text { Peso } \\
\text { Ovos } \\
(\mathbf{g})\end{array}$ & $\begin{array}{c}\text { Espessura } \\
\text { Casca }(\mathbf{m m})\end{array}$ & $\begin{array}{c}\text { \% } \\
\text { Casca }\end{array}$ & $\begin{array}{c}\text { Unidade } \\
\text { Haugh }\end{array}$ & Densidade \\
\hline 0 & 11,17 & 0,28 & 7,89 & 87,85 & 1,072 \\
300 & 11,07 & 0,28 & 8,08 & 87,33 & 1,073 \\
600 & 11,33 & 0,29 & 7,92 & 87,44 & 1,072 \\
\hline $\mathrm{P}$ & 0,70 & 0,46 & 0,46 & 0,72 & 0,23 \\
$\mathrm{CV}(\%)$ & 3,36 & 2,89 & 3,70 & 1,65 & 0,20 \\
\hline
\end{tabular}

Estudos com outro ansiolítico, a passiflora, na alimentação de codornas poedeiras (Silva, 2006; Hada et al., 2007) mostraram que, assim como a kava-kava, as diferentes inclusões de passiflora não influenciaram a qualidade dos ovos.

Verificou-se efeito significativo entre os tratamentos quanto ao tempo em imobilidade tônica. As aves alimentadas com a maior dosagem de kava-kava na dieta obtiveram os menores valores para TIT quando comparadas às aves que receberam os demais tratamentos, porém, a relação entre heterófilos e linfócitos não foi influenciada pelos diferentes tratamentos (Tabela 3). Da mesma forma, Silva (2006) observou menor TIT para as aves alimentadas com as maiores dosagens de passiflora na dieta (500 e $750 \mathrm{mg}$ de passiflora/kg de ração) e também não observou influência do fitoterápico na relação entre heterófilos e linfócitos. Esse fato evidencia que a passiflora, bem como a kava-kava, foram capazes de acalmar as codornas.

Outras pesquisas com a inclusão de fitoterápico com propriedades ansiolíticas e sedativas na dieta de codornas japonesas durante a postura, tais como o extrato seco de camomila e valeriana, mostraram que estes fitoterápicos nas dosagens de 0,250,500 e $750 \mathrm{mg} / \mathrm{kg}$ de ração não influenciaram o tempo de permanência das aves em imobilidade tônica e a relação entre heterófilos e linfócitos (Marques, 2007; Gravena, et al. 2009).

TABELA 3: Valores médios obtidos para tempo em imobilidade tônica (TIT) e relação heterófilo:linfócito (H:L) de codornas submetidas a diferentes níveis de kavakava na dieta durante a fase de postura.

\begin{tabular}{ccc}
\hline kava-kava (mg) & TIT (segundos) & H:L \\
\hline 0 & $49,95 \mathrm{c}$ & 0,43 \\
300 & $38,46 \mathrm{~b}$ & 0,35 \\
600 & $32,28 \mathrm{a}$ & 0,35 \\
\hline P & 0,039 & 0,177 \\
CV (\%) & 22,38 & 60,53 \\
\hline
\end{tabular}

Médias seguidas de letras desiguais na coluna diferem significativamente $(\mathrm{P}<0,05)$.

Segundo Macari e Luquetti (2002), a contagem diferencial de leucócitos no sangue de frangos mostra que a proporção normal de heterófilos:linfócitos está em torno de 1:2. Com isso, podemos afirmar que a relação entre heterófilos e linfócitos de codornas alimentadas ou não com kava-kava está normal, o que indica que as aves não estavam em estresse crônico. 
Não houve correlação entre valores percentuais para intensidade de ferimentos e diferentes inclusões de kava-kava na dieta (Tabela 4). Da mesma forma, Gravena et al. (2009) e Marques (2007) também não observaram diferenças na intensidade de ferimentos de codornas alimentadas com valeriana e camomila na dieta.

TABELA 4: Valores percentuais obtidos para a intensidade de ferimentos e agressividade de codornas submetidas a diferentes níveis de kava-kava na dieta durante a fase de postura.

\begin{tabular}{cccc}
\hline \multirow{2}{*}{ Escores } & \multicolumn{3}{c}{ kava-kava (mg) } \\
\cline { 2 - 4 } & $\mathbf{3}$ & $\mathbf{3 0 0}$ & $\mathbf{6 0 0}$ \\
\cline { 2 - 4 } Cabeça \\
Sem lesão & 60,00 & 69,17 & 69,17 \\
Com lesão & 40,00 & 30,83 & 30,83 \\
Total & 100 & 100 & 100 \\
Valor de Qui-quadrado & \multicolumn{3}{c}{0,75} \\
P value & \multicolumn{3}{c}{ Corpo } \\
\hline & \multicolumn{3}{c}{67,50} \\
\hline Sem lesão & 71,67 & 69,17 \\
Com lesão & 28,33 & 32,49 & 30,83 \\
Total & 100 & 100 & 100 \\
\hline Valor de Qui-quadrado & \multicolumn{3}{c}{0,26} \\
P value & \multicolumn{3}{c}{0,8373} \\
\hline
\end{tabular}

Conclui-se que a kava-kava utilizada como fitoterápico na alimentação de codornas de postura não tem efeito sobre o desempenho, qualidade de ovos, intensidade de ferimentos e relação heterófilo:linfócito, entretanto ocorre redução da imobilidade tônica o que predispõe a uma redução do estresse.

\section{Referências}

Arruda, A. M.; Zanette, V. C.; Rossato, A. E.; Amaral, P. A. 2005. Piper methysticum L. (kava-kava): histórico do uso e aspectos taxonômicos, farmacológicos e toxicológicos. Pesquisa e Extensão em Saúde, 2: 59-68.

Belo, M. T. S.; Cotta, J. T. B.; Oliveira, A. I. G. 2000. Níveis de energia metabolizável em rações de codornas japonesas (Coturnix coturnix japonica) na fase inicial de postura. Ciência e Agrotecnologia, 24: 782-793.

Borges, S. A.; Maiorka, A.; Silva, A. V. F. 2003. Fisiologia do estresse calórico e a utilização de eletrólitos em frangos de corte. Ciência Rural, 33: 975-981.

Campo, J. L.; Dávila, S. G. 2002. Influence of mating ratio and group size on indicators of fearfulness and stress hens and cocks. Poultry Science, 81 (8): 1099-1103.
Clouatre, D. L. 2004. Kava kava: examining new reports of toxicity. Toxicology Letters, 150 (1): 85-96.

Gravena, R. A.; Marques, R. H.; Silva, J. D. T.; Hada, F. H.; Silva, V. K.; Munari, D. P.; Moraes, V. M. B. 2009. Uso da Valeriana officinalis em dietas de codornas japonesas na fase de postura. Biotemas, 22 (4): 185-191.

Hada, F. H.; Matos, A. S.; Silva, J. D. T.; Marques, R. H.; Gravena, R. A.; Moraes, V. M. B. 2007. Efeito de diferentes níveis de Passiflora alata sobre o desempenho e qualidade de ovos de codornas. Anais da 44 ${ }^{\text {a }}$ Reunião Anual da Sociedade Brasileira de Zootecnia, Jaboticabal, Brasil, CD-Rom.

Heiblum, R.; Aizenstein, O.; Gvaryahu, G.; Voet, H.; Robinzon, B.; Snapir, N. 1998. Tonic immobility and open field responses in domestic fowl chicks during the first week of life. Applied Animal Behaviour Science, 60 (4): 347-357.

Jones, R. B.; Mills, A. D. 1999. Divergent selection for social reinstatement behaviour in Japanese quail: effects on sociality and social discrimination. Poultry and Avian Biology Reviews, 10 (4): 213-223.

Laganá, C.; Pizzolante, C. C.; Kakimoto, S. K.; Togashi, C. K.; Turco, P. H. N.; Saldanha, E. S. P. B.; Alvares, V. 2009. Influência de métodos de debicagem e tipo de bebedouro no desempenho de codornas japonesas em fase de produção. Anais do VII Congresso de Produção, Comercialização e Consumo de Ovos, São Pedro, Brasil, p.182-184.

Landers, K. L.; Moore, R. W.; Dunkley, C. S.; Herrera, P.; Kim, W. K.; Landers, D. A.; Howard, Z. R.; Mcreynolds, J. L.; Bryd, J. A.; Kubena, L. F.; Nisbet. D. J.; Ricke, S. C. 2007. Immunological cell and serum metabolite response of 60-week-old commercial laying hens to an alfalfa meal molt diet. Bioresource Technology, 99 (3): 604-608.

Lim, S. T.; Dragull, K.; Tang, C. S.; Bittenbender, H. C.; Efird, J. T.; Nerurkar, P. V. 2007. Effects of kava alkaloid, pipermethystine and kavalactones on oxidative stress and cytochrome P450 in F-344 rats. Toxicological Science, 97 (1): 214-221.

Macari, M.; Luquetti, B. C. 2002. Fisiologia cardiovascular. In: Macari, M.; Furlan, R. L. \& Gonzales, E. (Eds). Fisiologia aviária aplicada a produção de frangos de corte. $2^{\mathrm{a}}$ ed. Funep/UNESP, Jaboticabal, Brasil, p.17-36.

Marques, R. H. 2007. Uso da camomila (Matricaria chamomila) em dietas de codornas japonesas. Monografia, Universidade Estadual Paulista, Jaboticabal, Brasil, 50pp.

Maxwell, M. H. 1993. Avian blood leukocyte responses to stress. World's Poultry Science Journal, 49: 34-43.

Murakami, A. E. 1991. Níveis de proteína e energia em dietas de codornas japonesas (Coturnix coturnix japonica) nas fases de crescimento e postura. Tese de Doutorado, Faculdade de Ciências Agrárias e Veterinárias, Universidade Estadual Paulista, Brasil, 92pp.

Pittler, M. H.; Ernst, E. 2000. Efficacy of kava extract for treating anxiety: systematic review and meta-analysis. Journal of Clinical Psychopharmacology, 20 (1): 84-89.

Rostagno, H. S.; Albino, L. F. T.; Donzele, J. L.; Gomes, P. C.; Oliveira, R. F.; Ferreira, A. S.; Barreto, S. L. T. 2005. Tabelas brasileiras para aves e suínos: composição de alimentos e exigências nutricionais de aves e suínos. $2^{\mathrm{a}}$ ed. UFV, Viçosa, Brasil, 186pp.

Ruiz, G.; Rosenmann, M.; Novoa, F. F.; Sabat, P. 2002. Hematological parameters and stress index in rufous-collared sparrows dwelling in urban environments. Cooper Ornithological Society, 104: 162-166. 
Savory, C. J.; Mann, J. S.; Macleod, M. G. 1999. Incidence of pecking damage in growing bantams in relation to food form, group size, stocking density, dietary tryptophan concentration and dietary protein source. British Poultry Science, 40 (5): 579-584.

Scherer, J. 1998. Kava-kava extract in anxiety disorders: an outpatient observational study. Advances in Natural Therapy, 15 (4): 261-269.

Schmid, I.; Wechsler, B. 1997. Behaviour of Japanese quail (Coturnix japonica) kept in semi-natural aviaries. Applied Animal Behaviour Science, 55: 103-112.

Scope, A.; Filip, T.; Glaber, C.; Resch, F. 2002. The influence of stress from transport and handling on hematologic and clinical chemistry blood parameters of racing pigeons (Columbra ivia domestica). Avian Diseases, 46: 224-229.
Silva, J. D. T. 2006. Uso da Passiflora alata na alimentação de codornas japonesas nas fases de recria e postura. Dissertação de Mestrado, Universidade Estadual Paulista, Jaboticabal, Brasil, 58pp.

Statistical Analysis Systems Institute. 1995. User's guide. Version 6. $4^{\text {th }}$ ed. SAS ${ }^{\circledR} / S T A T$, SAS Institute Incorporation, Cary, USA, 365pp.

Ulbricht, C.; Basch, E.; Boon, H.; Ernst, E.; Hammerness, P.; Sollars, D.; Tsourounis, C.; Woods, J.; Bent, S. 2005. Safety review of kava (Piper methysticum) by the nature standard research collaboration. Expert Opinion on Drug Safety, 4 (4): 779-794.

Vleck, C. M.; Vertalino, N.; Vleck, D.; Bucher, T. L. 2000. Stress, corticosterone and heterophil to lymphocyte ratios. In: Free-living Adelie Penguins. Cooper Ornithological Society, 102: 392-400. 